Note: This is a pre-copy-editing, author-produced PDF of an article accepted for publication in Drugs: Education, prevention and policy following peer review. The definitive publisher-authenticated version [Morgan M, Hibell B, Andersson B, Bjarnason T, Kokkevi A and Narusk A (1999) The ESPAD study: implications for prevention, Drugs: Education, prevention and policy, 6(2), 243-256] is available online at http://www.informaworld.com/smpp/title content=t713412630

\title{
The ESPAD Study: implications for prevention
}

\author{
MARK MORGAN ${ }^{1}$, BJORN HIBELL ${ }^{2}$, BARBRO ANDERSSON ${ }^{2}$, THORODDUR BJARNASON ${ }^{3}$, \\ ANNA KOKKEVI ${ }^{4} \&$ ANU NARUSK $^{5}$
}

\section{Published in: Drugs: Education, prevention and policy, 1999, vol. 6, no. 2, pp.243-256}

${ }^{1}$ St Patrick's College, Dublin, Ireland; ${ }^{2}$ CAN, Stockholm, Sweden; ${ }^{3}$ University of Notre Dame, Indiana, USA;

${ }^{4}$ Athens University Medical School, Athens, Greece; \& ${ }^{5}$ Institute of International and Social Studies, Estonia

\begin{abstract}
The Europe an Schools Project on Alcohol and other Drugs (ESPAD) was concerned with the substance use , beliefs, attitudes and risk factors among over 50,000 16-year-olds in 26 European countries. Based on this data, the present paper focuses on critical issues in prevent ion and uses a country-level analysis with focus on the extent that contextual and cultural factors interact with factors influencing the use of alcohol and other drugs. The results indicate that: (i) an emphasis on risks and dangers may be a poor prevent ion strategy since many young people do not believe the widely accepted dangers of certain forms of substance use (e.g. cigarette smoking); (ii) misperception of norms in relation to substance use , that is, the belief that use of alcohol and other drugs is more common than it actually is, emerged in most countries with the exception of Nordic countries; (iii) the correlation between perceived access to substances and actual use depended on the substance involved; correlations we re strongest for cannabis but low for alcohol; (iv) the measure of problem behaviour was used in the ESPAD study (truancy from school), is correlated with substance use in a way that is opposite to that predicted in problem behaviour theory; and (v) the re were no indications that the potential restraining factors that we re examined in this study (involvement in athletics and leisure) acted in a way that prevented people from experimenting with drugs. The results of this analysis suggests that far from our having identified a core set of universal influences that act to determine substance use, the importance of cultural and contextual factors have been underestimated as has the importance of the specific substance involved.
\end{abstract}

\section{Introduction}

Recent views of substance use prevention programmes have produced mixed conclusions. The reviews by Moskowitz (1989) and by Brown \& Kreft (1998) are quite pessimistic regarding the efficacy of programmes, especially school-based interventions. On the other hand, the reviews by Hansen (1992) and by Morgan (1998), while demonstrating the potential of prevention programmes in certain circumstances, also show the need for greater understanding of the factors that influence experimental substance use, in order that the design of programmes would have a former grounding in the actual experiences of young people.

It is the major contention of this paper that part of the reason for the lack of effectiveness of programmes is the absence of broadly based research on the social and cultural factors that influence substance use and the limited understanding of risk-factors. The data base of the European School Project on Alcohol and other Drugs (ESPAD) provides a basis for sounder planning of such programmes since it involves culturally diverse populations, both legal and illegal substances, and because it sought information on social, cognitive and personal influences. Below, the ESPAD study is described briefly, following which a number of questions of direct relevance to current prevention are addressed on the basis of the ESPAD data.

Please use the following citation: Morgan M, Hibell B, Andersson B, Bjarnason T, Kokkevi A and Narusk A (1999) The ESPAD study: implications for prevention (Author postprint) in Drugs: Education, prevention and policy, 6(2), 243-256 [Accessed: (date) from 


\section{The ESPAD Study: methodological issues}

ESPAD describes the substance-use behaviours as well as related beliefs and attitudes among over 50,000 16-year-olds in 26 European countries (Hibell et al., 1997). A common questionnaire was used in each participating country; data collection took place in schools during the same time period using similar procedures.

The prevalence of drug use (legal and illegal) in the various participating countries comprises the main feature of the ESPAD report (Hibell et al., 1997). However, a number of broad conclusions of the study regarding sampling, methodology and data collection procedures are summarized here since they bear directly on the cross-country analysis to be utilized here.

Firstly, as regards sampling, national samples (as opposed to local or regional samples) were drawn in all countries, with one exception in which case a sample from the capital city only was targeted. The target population were students born in 1979, i.e. in the year of data collection they would be 16 years. However, not all persons born in 1979 were still in school and furthermore the rate of retention in school differs somewhat from country to country. While in most countries over $90 \%$ of the age cohort are still in school, in three countries the figure is much lower. Given that those who drop out of school are more likely to use substances than those who remain, this is likely to be a consideration in generalizing to the full cohort, but is less problematic in the present work which is not concerned with this issue.

Taking into account the cluster sampling and the need to provide information about strata it was decided to have a sample of 2400 in each country. Only five countries have samples that were smaller than the target. Furthermore, the response rates (proportion of students who completed the questionnaire out of all students in participating classes) for 13 of the countries were $90 \%$ or greater, The missing data rates are also quite satisfactory. The overall average across all countries is $3 \%$ (i.e. on average $97 \%$ of questions were completed). The proportion of missing data rates is extremely low (averaging about $1 \%$ ) for cigarette questions, quite low for most illegal substances and slightly higher for lifetime prevalence of drinking and being drunk (5\% and $3 \%$, respectively).

The agreed data collection was March to April, 1995. Almost all countries managed to adhere to these dates but in a few countries there was unavoidable re-scheduling. The data were collected through giving questionnaires to the group under the supervision of either a teacher or a research assistant. Because this difference (teacher or research assistant) was considered to be an important methodological issue, it was the focus of a study by Bjarnason (1995) who compared the responses of large samples who were administered the questionnaire by either teachers or research assistants. No significant differences emerged indicating that, at least in some countries, the effects of this factor were not important.

There are strong indications that the drug measures in the ESPAD study have substantial claims to both reliability and validity. Only a small percentage of answers were internally inconsistent (indicating that they had never used a substance and later saying that that they had used this substance at a specific age). In 14 of the countries consistent answers were provided by $92 \%$ or more of the students. In addition, very few students in any country reported 'dummy' drug use: in no country was the reported rate of 'dummy' drug use greater than $0.6 \%$ with an average of $0.3 \%$ across countries. Furthermore, in two studies which used these same items but with samples drawn differently, the same countries found remarkably similar rates of prevalence of substance. Finally, the construct validity was strong in the sense that the pattern of results was largely consistent with what would be predicted on the basis of theoretical understanding of the relationship of use with measures of influence.

In the broadest sense, a number of the results - emanating from the ESPAD study are of considerable interest. For example, one finding is that in terms of rates of prevalence, legal drugs, specifically cigarettes and alcohol, far outweigh the numbers involved with illicit substances. It is especially interesting that the 
uptake of cigarette smoking is substantial even in countries which have had decades of campaigns to warn of the dangers of tobacco. Another finding of relevance to prevention policy was in relation to the first illegal drug used among those young people who reported having used such substances. In every country, the vast majority of young people obtained the substance from peers or friends and only a minority said that a 'stranger' or a 'dealer' was involved. Thus, at least in relation to initiation, the peer group has indeed a central role, with consequent implications for training in resistance skills. A third finding of general relevance to prevention was in relation to gender differences. A broad generalization would be that gender interacted with cultural/political factors and the type of substance involved. Thus, more girls than boys smoked cigarettes in many Northern European countries while the opposite was the case in Eastern European countries. In the case of alcohol, some of the same pattern emerged but boys tended to outnumber girls in relation to frequency of being drunk. Finally, boys in nearly all countries tended to be more likely to report have used illegal substances. The implication of these findings is that efforts to tailor prevention policies will need to take gender-linked social norms into account in order to maximize effectiveness of interventions.

In addition to these general findings, the ESPAD study allows consideration of a number of specific matters about the way in which the effectiveness of prevention programmes might be enhanced. The rest of this paper is devoted to these issues.

\section{Models of Misuse and Prevention}

Prevention programmes usually take as their point of departure an understanding of the risk factors associated with the target behaviour. However, recent evidence suggests that in the case of substance use, a variety of contextual and cultural factors interact with factors influencing the use of alcohol and other drugs (Lerner \& Galambos, 1998). For example, there is evidence that peer substance use is relatively less important in the case of African American adolescents than is the case with European American youth (Barnes et al., 1994). Furthermore, religious commitment exerts a stronger protective influence against the use of alcohol among African American youth (Barnes et al., 1994). In addition, there is evidence that the relative importance of various influences changes over the course of adolescence (Morgan \& Grube, 1989).

These findings have important implications for prevention, since such programmes are largely based on models of how experimental substance use comes about. To the extent that cultural and contextual factors interact with influences, prevention programmes will need to be specifically tailored to meet each situation and target group. The present analysis examines widely held views regarding prevention, and examines the extent to which the evidence from the 26 participating countries supports the assumptions regarding the importance of the factors that have been regarded as critical in experimental substance use.

The analytic strategy consists of a country-level analysis, i.e. do those countries in which a particular percentage of students believe/behave in a certain way, have a pattern of substance use that would be predicted on the basis of the factor in question being an important influence in beginning substance use among adolescents. In other words, while most existing studies take the individual as the unit of analysis, here we take the country as a whole (i.e. percentage using a given substance) as the unit and attempt to pinpoint the factors associated with use across countries. Thus, instead of asking whether perception of peer approval is associated with the individual's reported use, the analysis will inquire as to whether the countries with a high percentage of young people who approve of use also have a higher level of use of a given substance.

The analysis will be guided by an attempt to test the following assumptions which are central to many approaches to prevention: (i) Is an emphasis on the risk/danger of substance use likely to be an effective influence strategy? (ii) Is the ability to perceive norms accurately and to withstand normative influences a major factor in prevention of substance use? (iii) Can risk-factors for substance use be identified and targeted in prevention?; and (iv) Can effective restraining factors be identified? 


\section{ESPAD Findings in Relation to Prevention Models}

\section{Risk, Danger and Substance Use}

It is often assumed that perception of consequences, specifically dangerous consequences, plays an important part in such behaviour, deterring the onset and development of substance use. The rationale associated with risk perception is that when people perceive a risk, the associated fear will lead to belief and attitude change which in turn will result in behaviour change (e.g. Baron \& Byrne, 1997).

The ESPAD study addressed the matter of risk perception in two ways. Firstly. information was obtained on the extent to which young people accepted the risk message, namely, did they actually think that substance use was indeed a serious risk. Secondly, it was possible to analyse the data across countries to see whether the level of risk perception was associated with reported substance use.

Table 1 shows the percentage of respondents in each country who were of the view that a certain substance-use behaviour was a 'great risk'. As can be seen the questions included heavy smoking, 'heavy' drinking, occasional and regular use of cannabis, and occasional and regular use of ecstasy. Each of these is of particular interest. For example, what has been the success of the campaigns to convince young people of the dangers of heavy smoking, heavy drinking and ecstasy use?

Table 1. Perceived risks of substance use

\begin{tabular}{|c|c|c|c|c|c|c|}
\hline & $\begin{array}{l}\text { Twenty }+ \\
\text { cigarettes daily }\end{array}$ & $\begin{array}{l}\text { Five }+ \text { drinks at } \\
\text { weekend }\end{array}$ & $\begin{array}{l}\text { Occasional } \\
\text { marijuana }\end{array}$ & $\begin{array}{l}\text { Regular } \\
\text { marijuana }\end{array}$ & $\begin{array}{l}\text { Occasional } \\
\text { ecstasy }\end{array}$ & $\begin{array}{l}\text { Regular } \\
\text { ecstasy }\end{array}$ \\
\hline Croatia & 57 & 44 & 55 & 82 & 59 & 79 \\
\hline Cyprus & 63 & 71 & 53 & 87 & 51 & -- \\
\hline Czech Republic & 75 & 39 & 37 & 78 & 47 & 80 \\
\hline Denmark & 70 & 13 & 21 & 71 & 36 & 69 \\
\hline England & 55 & 20 & 23 & 44 & 53 & 78 \\
\hline Estonia & 71 & 38 & 44 & 78 & 29 & 55 \\
\hline Finland & 68 & 30 & 49 & 91 & 60 & 89 \\
\hline Hungary & 77 & 55 & 62 & 89 & 60 & 86 \\
\hline Iceland & 74 & 37 & 42 & 89 & 86 & 53 \\
\hline Ireland & 61 & 16 & 19 & 57 & 45 & 81 \\
\hline Italy & 63 & 33 & 49 & 83 & 58 & 85 \\
\hline Lithuania & 74 & 54 & 63 & 76 & 57 & 74 \\
\hline Malta & 53 & 40 & 60 & 61 & 59 & 79 \\
\hline Norway & 56 & 29 & 36 & 87 & 39 & 85 \\
\hline Northern Ireland & 66 & 23 & 36 & 61 & 59 & 85 \\
\hline Poland & 84 & 46 & 64 & 93 & 65 & 93 \\
\hline Portugal & 69 & 53 & 67 & 89 & 69 & 90 \\
\hline Scotland & 60 & 20 & 14 & 32 & 53 & 78 \\
\hline Slovak Republic & 68 & 45 & 53 & 87 & 56 & 85 \\
\hline Slovenia & 49 & 40 & 48 & 79 & 47 & 79 \\
\hline Sweden & 65 & 45 & 52 & 92 & 58 & 91 \\
\hline Turkey & 75 & 62 & 76 & 89 & 74 & -- \\
\hline Ukraine & 46 & 58 & 61 & 80 & 60 & 76 \\
\hline Wales & 69 & 12 & 23 & 47 & 53 & 82 \\
\hline Greece & 56 & & 47 & 82 & & \\
\hline
\end{tabular}

Note: Numbers shown are percentages who thought that the behaviour in question was a 'great risk' .

Two points are especially worthy of comment in relation to the perception of risk in the participating countries. Firstly, it is evident that a substantial minority in each country did not perceive that smoking a pack or more $(20+)$ of cigarettes daily was a great risk, i.e. they thought that it involved a 'slight' or 'moderate' or 'no risk'. In other words, despite the extensive information campaigns conducted over the 
last decades, a great many young people were not convinced that heavy smoking was dangerous. In the UK samples and in Ireland as well as in Norway and Sweden, between one-third and two-fifths of young people were not convinced that such smoking was a great risk. It is of some interest that these are countries were there has been a sustained and intense anti-smoking campaign.

A second point concerns the differences in the perception of risk associated with occasional use ("one or two times') and regular use. It is of particular interest that in every country, substantially more respondents thought that regular cannabis use was dangerous in comparison with the percentage who thought that occasional use was dangerous. This suggests that the critical feature in the perception of risk is not simply the substance but the frequency of use of that substance. A broadly similar pattern was found in relation to ecstasy.

Table 2. Correlations between perceived risk of substance use and actual behaviour

\begin{tabular}{|ll|ll|ll|}
\hline Lifetime smoking & $0.40^{*}$ & Lifetime drinking & -0.34 & Lifetime cannabis & $-0.88^{*}$ \\
Recent smoking & 0.04 & Drinking last year & $-0.45^{*}$ & Cannabis last year & $-0.89^{*}$ \\
& & Drinking last month & $-0.57^{*}$ & Cannabis last month & $-0.89^{*}$ \\
& & Lifetime drunk & $-0.75^{*}$ & Cannabis $<13$ years & $-0.88^{*}$ \\
& & Drunk last year & $-0.82^{*}$ & Lifetime other drug use & $-0.88^{*}$ \\
& & Drunk last month & $-0.80^{*}$ & & \\
& & Drank beer < 13 years & -0.21 & \\
& & Drunk at < 13 years & $-0.76^{*}$ & & \\
& & & & & \\
& & & & &
\end{tabular}

Note: Table entries are the correlations (country level) between percentage who thought that use of the substance was a 'great risk' and actual use. In the case of smoking the risk focus was `smoking 201 cigarettes daily', for drinking the focus of risk was 'drinking 51 drinks at the week-end', while in the case of cannabis the focus was 'use once or twice'. $* p<0.05$.

Association of perception of risk with use. It is also of interest to consider the association at country level between perception of risk and drug use. Is it the case that in those countries where a relatively higher proportion regard use of a certain substance as risky, the use of that substance is relatively lower? Table 2 shows the association between risk perception and reported substance use at country level, for cigarettes, alcohol and cannabis use.

Perhaps the most interesting feature emerging from Table 2 is that the association between perceived risk and substance use depends on the substance and level of use involved. Furthermore, the difference in the magnitude of the correlations is quite dramatic. There is an indication that the correlation between perceived risk and actual use are most strongly negative at frequent and (in the case of alcohol) heavy levels of use.

Thus, with regard to cigarette smoking, the correlation with lifetime smoking is actually positive, i.e. the countries in which young people see a risk of smoking have a higher level of reported smoking. The picture is quite different in relation to recent smoking. In this case the correlation is not substantial or significant. These results imply that even if it is accepted by young people that smoking is dangerous, it does that not follow that they will not take up the habit. Thus, there are two important findings regarding the issue of perception of risk and smoking. Firstly, a substantial number of young people do not accept that smoking is a 'great risk'. Secondly, in those countries where relatively more young people accept that there is a great risk from smoking, the prevalence of smoking is just as great (or even greater) than in other countries where the message regarding risk is not endorsed to the same extent.

However, the association between perceived risk and prevalence is much stronger and negative in the case of both alcohol and illegal drugs. In the case of alcohol the correlations are negative but modest in relation to broad measures (lifetime prevalence of drinking, and previous month drinking) but are stronger in relation to both heavy levels of drinking (e.g. being drunk). This makes sense because the risk measure is particularly focused on heavy drinking (five drinks + ). Thus, it would seem that in those countries where 
the message about heavy drinking is accepted by young people, there is less of a tendency for them to get drunk.

With regard to illegal drugs, the picture that emerged was that the perception of risk of illegal substances was closely related to low levels of use. This was true for all four measures of risk (cannabis and ecstasy, occasionally and regularly). One such measure is shown for illustration in Table 2, namely, 'use cannabis once or twice'. From this it can be seen that the association between perceived risk and actual use is strong and negative, not only with regard to cannabis but also for other illegal substances.

Thus, it would seem that perceived risk operates quite differently in relation to cigarettes, alcohol and illegal substances. Risk perception seems to play a negligible part in cigarette smoking, an important part in heavy drinking and getting drunk, and a very important part in all aspects of drug use. While the present data do not allow for an explanation of why this is the case, it may not be coincidental that the risks of cigarette smoking are long term while the potential risks associated with heavy drinking and with drug use include short-term risks (e.g. personal injury) as well as long-term hazards.

\section{How Widespread is Misperception of Norms Regarding Drug Use?}

Normative approaches to prevention are based on the assumption that many young people overestimate the level of social support for substance-use behaviour. The correction of such misperceptions is said to reduce substance use because of the powerful impact of normative influences on behaviour (Graham $e t$ al., 1991; Donaldson e t al., 1995, Morgan \& Grube, 1991).

One feature of particular interest is the misperception of norms in relation to substance use, that is, the belief that use of alcohol and other drugs is more common than it actually is. One demonstration of this phenomenon is the 'false consensus effect', i.e. the belief by users of a particular drug that use by others is more frequent than is actually the case. Conversely, those who are not themselves frequent users are inclined to believe that they are quite unique with the net outcome that substance use may be a general overestimation of actual use. This has been referred to as 'pluralistic ignorance' in some publications (e.g. Prentice \& Miller, 1993).

Only modest evidence is available for this effect in the extant literature. In the ESPAD study students were asked not only about their own drug use but also about the extent to which their friends use these substances. This allows some opportunity for examining the extent to which any such distortions occur. 
Table 3. Perceived and actual substance use

\begin{tabular}{|c|c|c|c|c|}
\hline & \multicolumn{2}{|c|}{ Smoking } & \multicolumn{2}{|c|}{ Being Drunk } \\
\hline & Perceived & Actual & Perceived & Actual \\
\hline Croatia & 52 & 32 & 12 & 4 \\
\hline Cyprus & 37 & 23 & 8 & 2 \\
\hline Czech Republic & 40 & 34 & 11 & 10 \\
\hline Denmark & 27 & 28 & 23 & 21 \\
\hline England & 45 & 37 & 37 & 22 \\
\hline Estonia & 43 & 28 & 9 & 4 \\
\hline Faroe Islands & 43 & 42 & 33 & 11 \\
\hline Finland & 31 & 37 & 15 & 18 \\
\hline Hungary & 41 & 34 & 10 & 5 \\
\hline Iceland & 26 & 32 & 10 & 14 \\
\hline Ireland & 43 & 41 & 18 & 15 \\
\hline Italy & 64 & 36 & 10 & 8 \\
\hline Lithuania & 35 & 25 & 16 & 9 \\
\hline Malta & 50 & 31 & 8 & 4 \\
\hline Norway & 26 & 36 & 7 & 8 \\
\hline Northern Ireland & 32 & 30 & 31 & 19 \\
\hline Poland & 27 & 28 & 5 & 7 \\
\hline Portugal & 29 & 24 & 4 & 3 \\
\hline Scotland & 32 & 33 & 45 & 29 \\
\hline Slovak Republic & 18 & 27 & 4 & 4 \\
\hline Slovenia & 29 & 19 & 10 & 7 \\
\hline Sweden & 26 & 30 & 15 & 13 \\
\hline Turkey & 50 & 37 & 5 & 4 \\
\hline Ukraine & 50 & 38 & 6 & 2 \\
\hline Wales & 42 & 36 & 30 & 16 \\
\hline Greece & 30 & 23 & & \\
\hline
\end{tabular}

Note: Table entries for `perceived' smoking are percentages in each country who said that `most or all of their friends smoke cigarettes', 'actual smoking' refers to the percentage of respondents who reported that they actually smoked during the previous month. 'Perceived getting drunk' refers to the percentage who indicate that most of their friends get drunk' at least once a month', while the 'actual percentage getting drunk' is the percentage of participants who reported being drunk at least once during the previous month (check questions).

Two examples are given here by way of illustration. Respondents were asked about how many of their friends `smoke cigarettes' and also how many 'get drunk at least once a week'. Table 3 shows the percentage of students in each country who said that 'most or all' of their friends smoke cigarettes while the corresponding percentage of those students who had actually smoked during the previous month is given for each country. With regard to 'being drunk' the percentage of students in each country who perceived that most or all of their friends is compared with the percentage who actually said that they had been drunk ‘ $3 \pm 5$ times’ and more frequently, during the previous 30 days.

Overall, there is considerable evidence of overestimation. With regard to smoking, in 18 of the participating countries there was an overestimation. However, while the overestimation occurs in most countries, this did not happen in the case of several Nordic countries. In the case of Denmark, Finland, Faroe Islands, Iceland, Norway and Sweden, either there was no substantial overestimation or the percentage of young people who aid that 'most or all of their friends smoke' was actually less than the percentage who had reported smoking during the previous month.

With regard to being drunk, there is evidence of even greater distortion. In 20 of the 25 countries for which data were available, the percentage who perceived that most or all of their friends are drunk was greater than the actual number who indicated that this was the case. 
It is also of interest that those countries which did not show a major distortion effect in the case of smoking are mainly the same with regard to distortion of drinking. However, Faroe Islands is a major exception since the data from this country reveal a major exaggeration in relation to being drunk.

There are a number of possible explanations for this interesting pattern. For one thing, it may be that the adolescents in most countries are underestimating their own use and that this may happen to a lesser extent in Nordic countries. Another possibility is that substance use may be more secretive and therefore less visible in Nordic countries [1]. However, such explanations are merely speculative without further investigation.

An important question concerns the relationship between perception of peer substance use and students' own reported use. This information is given in Table 4, which shows that the pattern of correlations between perceived peer substance use and reported substance use in each country is strong, with 10 of the possible 12 correlations being statistically significant. However, it is interesting that the magnitude of the correlation is dependent on the substance involved and on the particular indicator in question. Thus, perception of peer use of cannabis is related remarkably strongly to all four indicators of illegal drug use.

In the case of perception of peer drunkenness, the correlation with percentage that reported ever having a drink (lifetime drinking) is not significant, and indeed the correlation with the percentage that reported drinking recently is also weak. However, the correlation with specific indices of being drunk are much stronger and the correlation with being drunk before age 13 is strongest of all. Finally, the correlation between perception of solvent use and actual solvent use is modest and is barely significant It is also interesting to note that the correlation between perceived peer smoking and actual smoking was rather similar to that for solvents, that is, the correlation with lifetime prevalence of cigarette smoking was not significant, while the correlation with recent cigarette smoking was $0.48(p<0.01)$.

Table 4. Perceived peer substance use and reported substance use

\begin{tabular}{|ll|ll|ll|}
\hline \multicolumn{2}{|c|}{ Peer use of cannabis } & \multicolumn{2}{c|}{ Peer frequency of being drunk } & \multicolumn{2}{c|}{ Peer solvent use } \\
\hline Lifetime drug use & $0.92^{*}$ & Lifetime drinking & 0.30 & Lifetime solvent use & $0.40^{*}$ \\
Lifetime cannabis use & $0.92^{*}$ & Recent drinking & $0.51^{*}$ & Last 12 months solvent use & $0.45^{*}$ \\
Last month cannabis use & $0.95^{*}$ & Lifetime been drunk & $0.71^{*}$ & Last month solvent use & 0.34 \\
Using cannabis before age 13 & $0.86^{*}$ & Last month, been drunk & $0.74^{*}$ & & \\
& & Been drunk before age 13 & $0.81^{*}$ & & \\
\hline
\end{tabular}

Note: Table entries are correlations (country level) between percentage who thought that some or most of their friends use the substance and percentage reporting such use.

$*_{p}<0.05$.

Table 5. Correlatioos of perceived access and use

\begin{tabular}{|ll|ll|ll|}
\hline Lifetime drug use & $0.90^{*}$ & Lifetime drinking & 0.21 & Lifetime solvent use & $0.50^{*}$ \\
Lifetime cannabis use & $0.90^{*}$ & Last year drinking & 0.24 & Last 12 months solvent use & $0.52^{*}$ \\
Last year cannabis use & $0.91^{*}$ & Last month drinking & 0.28 & Last month solvent use & 0.12 \\
Last month cannabis & $0.88^{*}$ & Beer last month & $0.49^{*}$ & & \\
Using cannabis before age 13 & $0.82^{*}$ & Drink beer before age 13 & 0.02 & \\
& & Been drunk before age 13 & 0.25 & & \\
\hline
\end{tabular}

Note: Table entries are correlations (country level) between percentage who thought that it would be easy to get

the substance in question and percentage reporting such use.

$* p<0.05$.

\section{Risk Factors, Access and Problem Behaviour}

Perceived access to substances has been established as an important risk factor in substance use (Morgan \& Grube, 1994; Petraitis et al., 1995). In particular, it has been shown that young people who see that alcohol and other substances are easy to obtain are more likely to use these than others who perceive such 
substances as more difficult to obtain. The demonstration that this applies at country level would suggest that national factors in access contribute to risk as well as having important implications for national policies.

The ESPAD study sought information on perceived ease of access by young people in each country on a five-point scale ranging from ‘impossible' to 'very easy' if they wanted to. Table 5 shows the correlations between this percentage in each country who though it would be `fairly easy' or `very easy' to get a particular substance and actual use of that substance.

It can be seen from Table 5 that the correlation between access and use is dependent on the substance. In the case of cannabis, the pattern of correlations is very strong, indicating that in those countries in which cannabis is seen as easily available, the percentage using the substance is relatively greater. In the case of solvents, the correlations are moderately strong except for last month use (which may be explained by the relatively low levels of use involved in this indicator). However, the correlations between perceived access to beer and drinking of beer were rather weak with only a single correlation emerging as significant.

To some extent, these correlations might be expected on the basis of the methods by which young people gain access to such substances. In the case of illegal drugs (such as cannabis) peers are frequently the source of such substances. This is not, however, the case with solvents or cigarettes. Similarly, in the case of alcohol peers may not be involved in occasional use but may be an important influence with regard to drunkenness, especially being drunk at a young age.

Problem behaviour theory suggests that adolescents who are prone to one problem behaviour (e.g. substance misuse) are also prone to other problem behaviours (Jessor et al., 1991). Thus, it is to be expected that adolescents who use cannabis or get drunk regularly are more likely to indulge in other behaviours like petty crime, defiance, fighting and truancy.

An especially relevant measure of problem behaviour is school truancy. In the ESPAD survey, a question focused on the number of school days (if any) that students had missed over the last 30 days, including the number that they missed specifically because the 'skipped' or 'cut' classes. Table 6 displays the correlation between the percentage of students in each country who reported being truant on 3 days or more during the previous month, and percentage indicating that they had used a substance within that time period. What is most remarkable about this pattern is that the correlations are negative, i.e. the opposite of what was predicted. In fact, one correlation (between truancy and having been drunk before age 13 years) turns out to be statistically significant in the direction opposite to that predicted by problem behaviour theory.

Table 6. Substance use and truancy

\begin{tabular}{|ll|ll|lc|}
\hline \multicolumn{2}{|c|}{ Peer use of cannabis } & \multicolumn{2}{c|}{ Peer frequency of being drunk } & \multicolumn{2}{c|}{ Peer solvent use } \\
\hline Lifetime drug use & -0.17 & Lifetime drinking & -0.28 & Lifetime solvent use & -0.19 \\
Lifetime cannabis use & -0.17 & Recent drinking & -0.26 & Last 12 months solvent use & -0.25 \\
Last month cannabis use & -0.12 & Lifetime been drunk & -0.39 & Last month solvent use & 0.04 \\
Using cannabis before age 13 & -0.26 & Last month, been drunk & -0.40 & & \\
& & Been drunk before age 13 & $-0.42^{*}$ & & \\
\hline
\end{tabular}

Note: The correlations reported are between substance use and the percentage in each country who reported missing 3 days or more because of truancy.

$* p<0.05$. 
Table 7. Correlations between participation in sports/athletics, and reading books with substance use

\begin{tabular}{|ll|ll|ll|}
\hline \multicolumn{2}{|c|}{ Peer use of cannabis } & \multicolumn{2}{c|}{ Peer frequency of being drunk } & \multicolumn{2}{c|}{ Peer solvent use } \\
\hline Lifetime drug use & 0.24 & Lifetime drinking & 0.12 & Lifetime solvent use & 0.25 \\
& $(-0.04)$ & & $(0.13)$ & & \\
Lifetime cannabis use & 0.19 & Recent drinking & 0.15 & Last 12 months solvent use & 0.25 \\
& $(-0.08)$ & & $(0.04)$ & & $(0.14)$ \\
Last month cannabis use & 0.27 & Lifetime been drunk & $0.44^{*}$ & Last month solvent use & 0.01 \\
& $(0.03)$ & & $(0.25)$ & & $(0.04)$ \\
Using cannabis before age 13 & 0.36 & Last month, been drunk & $0.48^{*}$ & \\
& $(0.09)$ & & & \\
& & Been drunk before age 13 & $(0.21)$ & & \\
& & & $(0.12)$ & & \\
& & & & \\
& & & & \\
\end{tabular}

Note: Main table entries are correlations between substance use and participation in sports and athletics while correlations with frequency of reading books for enjoyments are shown in parentheses.

$* p<0.05$.

\section{How Important are Re straining Factors in Substance Use?}

A number of versions of social control theory have been put forward to account for experimental substance use. A central feature of such theories is that they propose that young people are unlikely to get involved in such behaviour to the extent that they have strong bonds with institutions and individuals who might be expected to discourage such behaviour (Elliott $e$ t al., 1989). In these explanations strong conventional bonds mean a commitment to society, and its institutions, especially schools and religion. It also implies an attachment to conventional role models including teachers and family members.

For example, in the social developmental model proposed by Hawkins \& Weis (1985), it is suggested that adolescents become attached to substance-using peers if they are uncommitted to society and do not identify with conventional role models. Specifically, the model suggests that adolescents are especially likely to get involved with substance-using peers if they have infrequent opportunities for rewarding interaction at home and in school and few of the necessary interpersonal and academic skills for such interactions.

It is also of particular interest that the social developmental model focuses on interpersonal and academic skills since it implies quite reasonably that some of the origins of substance use are found in individual differences among adolescents themselves and are not dependent on their social institutions, economic conditions and neighbourhoods. In other words, when young people lack interpersonal and academic skills or when these skills are not rewarded by parents and teachers, adolescents may see that they have little to lose by becoming involved with deviant peers, thus resulting in relatively greater involvement in substance use.

The ESPAD study inquired about a number of behaviours that could be regarded as central to school success including: (i) participation in sports and athletics and (ii) reading books for enjoyment. In the present analysis the measures involved were (i) the percentage in each country reporting participating in sports and athletics once a month or more often, and (ii) the percentage who read books (other than school books) for enjoyment once a month or more often.

From Table 7 it can be seen that, contrary to the restraining hypothesis, the correlations between participation in sports/athletic activities and substance use were mainly in the direction opposite to that predicted. In fact, only two of the 24 correlations were in the predicted direction. Furthermore, in the case of the two correlations that were statistically significant (indices of being drunk), these were opposite to that predicted by the restraining hypothesis. In other words, in those countries where a greater percentage of students reported a higher level of involvement in games, there was a tendency for more students to be involved in substance use.

One explanation might be that the indices of bonding/attachment to conventional institutions that were used in the ESPAD study are not those that might be regarded as most appropriate. Against this, it is worth 
pointing out that the particular behaviours selected here are typical of those that have been used in studies that support bonding/conventional attachment explanations of such behaviour.

\section{Conclusions}

The results of the ESPAD study indicate that an emphasis on risk/fear appeals has limited possibilities in prevention. This is because risk messages are not believed and even when they are accepted, there is not necessarily a decline in use of particular substances. Normative influences on substance use are apparently very powerful. It is all the more significant therefore, there is a widespread tendency to misperceive the prevalence of drug use. Finally, while some factors that have been identified at the individual level as risk factors for use, also emerge as substantial risk factors at country level (e.g. access), other factors do not (e.g. problem behaviour). It is also of interest that factors found to be important in restraining substance use at the individual level, did not emerge as important at the higher level of analysis. There were major differences between substances, especially in the pattern of findings for alcohol versus illicit substances. Differences were also found with regard to the particular level of consumption being considered, e.g. occasional versus frequent use.

Most of the research on risk factors to date have utilized an individualistic research design in which factors differentiate young people who use various substances from those who do not. Important additional issues arise when comparisons are made between cultures and populations. The present results indicate that while some results from the individualistic tradition are supported in the cross-cultural comparison, others fare less well. Another ESPAD data collection phase has just been completed. This new phase of data collection may provide opportunities to clarify further some of the issues raised here. 


\section{Acknowledgement}

Thanks are due to an anonymous referee for comments on an earlier draft.

\section{Note}

[1] This point was suggested by an anonymous referee.

\section{References}

BARON, R.A. \& BYRNE, D. (1997). Social Psychology $\left(8^{\text {th }}\right.$ edn $)$ London: Allyn \& Bacon.

BARNES, G.M., FAREL L, M.P. \& BANERJEE, S. (1994). Family influences on alcohol abuse and other problem behaviours among black and white adolescents in a general population sample. Journal of Research on Adolescence, 4, pp. 183-202.

BJARNASON, T. (1995).

BROWN, J.H. \& KREFT, I.G.G. (1998). Zero effects of drug prevention programs: issues and solutions.

Evaluation Review, 22, pp. 3-14.

DONALDSON, S.I., GRAHAM, J.W., PICCININ, A.M. \& HANSEN, W.B. (1995). Resistance skills training and onset of alcohol use: evidence for beneficial and potentially harmful effects in public schools and in private Catholic schools. Health Psychology, 14, pp. 291-300.

ELLIOTT, D.S., HUIZINGA, D. \& AGETON, S.S. (1989) . Multiple Problem Youth: delinquency, substance use and mental health problems. New York: Springer-Verlag.

GRAHAM, J.W., MARKS, G. \& HANSEN, W.B. (1991). Social influence processes affecting adolescent substance use. Journal of Applied Psychology, 76, pp. 291-98.

HANSEN, W.B. (1992) . School-based substance abuse prevention: a review of the state of the art in curriculum, 1980 - 1990 . Health Educational Research, 7, pp. 403-30.

HAWKINS, J.D., CATALANO, R.F. \& MILL ER, J.Y. (1992). Risk and protective factors for alcohol and other drug problems in adolescence and early adulthood: implications for substance abuse prevention. Psychological Bulletin, 112, pp. 64-105.

HAWKINS, J.D. \& WEIS, J.G. (1985) . The social-developmental model: an integrated approach to delinquency prevention. Journal of Primary Prevention, 6, pp. 73-97.

HIBELL, B., ANDERSSON, B., BJARNASON, T., KOKKEVI , A., MORGAN, M. \& NARUSK, A. (1997). The ESPAD report: alcohol and other drug use among students in 26 European countries. Stockholm: CAN.

JESSOR, R., DONOVAN, J.E. \& COSTA, F.M. (1991). Beyond Adolescence: problem behavior and young adult development. Cambridge: Cambridge University Press.

LERNER, R.M. \& GALAMBOS, N.L. (1998). Adolescent development: challenges and opportunities for research, programs and policies. Annual Review of Psychology, 49, pp. 413-46.

MORGAN, M. (1998). Evaluation of substance use prevention programmes: implications for illicit substances. In A. SPRINGER \& F. UHL (Eds), Evaluation Research in Regard to Primary Prevention of Drug Abuse (pp. 91135) . Brussels: European Commission, Directorate-General Science, Research and Development.

MORGAN, M. \& GRUBE, J.W. (1989). Adolescent cigarette smoking: a developmental analysis of influences. British Journal of Developmental Psychology, 7, pp. 179-89.

MORGAN, M. \& GRUBE, J.W. (1991). Closeness and peer group influence. British Journal of Social Psychology, 30, pp. 159-69.

MORGAN, M. \& GRUBE , J.W. (1994). Drinking Among Dublin Postprimary School Pupils. Dublin: ESRI General Publications.

MOSKOWITZ, J.M. (1989). The primary prevention of alcohol problems: a critical review of the literature. Journal of Studies on Alcohol, 49, pp. 54-88.

PETRAITIS, J., FLAY, B.R. \& MILLER, T.Q. (1995). Reviewing theories of adolescent substance use: organizing pieces of the puzzle. Psychological Bulletin, 117, pp. 67-86.

PRENTICE, D.A. \& MILL ER, D.T. (1993). Pluralistic ignorance and alcohol use on the campus: some consequences of misperceiving the social norm. Journal of Personality and Social Psychology, 64, pp.243-56.

Please use the following citation: Morgan M, Hibell B, Andersson B, Bjarnason T, Kokkevi A and Narusk A (1999) The ESPAD study: implications for prevention (Author postprint) in Drugs: Education, prevention and policy, 6(2), 243-256 [Accessed: (date) from 